\title{
P04-49 LB. Adaptation of HIV-I envelope glycoprotein to humoral immunity at a population level
}

\author{
EM Bunnik*, Z Euler, M Welkers, M Grijsen, J Prins and H Schuitemaker
}

Address: AMC, Amsterdam, NH, Netherlands

* Corresponding author

from AIDS Vaccine 2009

Paris, France. 19-22 October 2009

Published: 22 October 2009

Retrovirology 2009, 6(Suppl 3):P389 doi:10.1 I86/1742-4690-6-S3-P389

This abstract is available from: http://www.retrovirology.com/content/6/S3/P389

(c) 2009 Bunnik et al; licensee BioMed Central Ltd.

\section{Background}

The HIV-1 envelope glycoprotein (Env) employs multiple mechanisms to escape from neutralizing antibodies (NAbs), including insertions in the variable domains of the gp120 subunit, and an increase in the density of the glycan shield. Here, we analyzed whether the resistance of Env to antibody neutralization has altered over the course of the epidemic.

\section{Methods}

We determined the neutralization sensitivity to HIVIg and the gp120-directed broadly neutralizing antibodies (BNAbs) b12 and 2G12 of clonal HIV-1 variants isolated from patients presenting with primary HIV-1 infection in Amsterdam between either 1985 - 1988 or 2003 - 2005. Moreover, we analyzed the length and glycosylation characteristics of gp120 of historical and recent HIV-1 variants, as well as the breadth of the neutralizing serum activity of historical and recent seroconverters in the Amsterdam Cohort.

\section{Results}

Viruses from recent seroconverters were more resistant to neutralization by HIVIg than viruses from historical seroconverters, but not to neutralization by BNAbs b12 or $2 \mathrm{G} 12$. The enhanced neutralization resistance of recent viruses coincided with an increased length of the variable loops in envelope, in particular the V1 loop, and an increased density of the viral glycan shield. Similar changes were observed between historical and contemporary subtype B and subtype C gp120 sequences of the Los Alamos database. In addition, historical seroconverters developed broader $\mathrm{NAb}$ responses than more recent seroconverters.

\section{Conclusion}

These finding suggest that over a period of 20 years, HIV1 has evolved towards a decreased exposure of antibody epitopes by enhancing the masking mechanisms of its envelope, although the epitopes of the gp120-direced BNAbs b12 and 2G12 seem to be preserved. The increased protection of Env against Abs appears to result in a blunted NAb response, suggesting that Env from historical viruses may be more promising immunogens for vaccine design than Env from currently circulating, neutralization resistant, HIV-1 variants. 